\title{
El Folklore, espejo de la vida e intérprete del Más Allá
}

No hay etapa del ciclo de la vida, desde el nacimiento a la muerte, que no tenga su interpretación y su reflejo en el folklore. Las comunidades auténticamente populares, a diferencia de la población de las grandes ciudades atareadas y tumultuosas, llevan una existencia apacible y lugareña. Al recorrer los pueblos y aldeas del interior de la Argentina, se tiene la impresión de salir del torbellino para aquietarse en la placidez del remanso. La atención colectiva no se proyecta, con dirección centrífuga, hacia lo externo, novedoso, foráneo; por el contrario, se repliega sobre sí misma y se preocupa de lo regional y cotidiano. El frenesí de la moda no hace mella en estas vidas desprovistas de artificio, modeladas por las fuerzas de su ambiente geográfico y de su tradición cultural. Los hechos corrientes, individuales y familiares, son conocidos por todos. A veces, incluso, zarandeados con fruición por el chismorreo; pero fuera de este mundillo del comentario pueblerino, hay ciertas maneras colectivas, tradicionales, practicadas desde tiempo inmemorial, mediante las cuales el pueblo interpreta a su modo los motivos que suscitan su interés. Costumbres y creencias, ceremonias y prácticas mágicas, cultos religiosos y ritos funerarios, cuentos y motes colectivos son algunas de las mil formas universales y eternas, con que el espíritu humano registra, comenta y a veces solemniza los acontecimientos que jalonan la existencia del hombre.

Los ejemplos podrían ordenarse en series infinitas. La bibliografía, sobre todo anecdótica y monográfica, es copiosí- 
sima. Este artículo de carácter panorámico, destinado a una revista de literatura, tendrá, pues, el carácter de una exposición más literaria que erudita. Lo cual no quiere decir que carezca de fundamento documental. Presupone por cierto abundante consulta de fuentes; pero he puesto el tono con preferencia en los datos que surgen de mis propias investigaciones folklóricas de campo. En quince años de viajes he conocido gran parte de mi país. Los datos documentados (siempre con e? apoyo de la fotografía y a veces de la cinematografía y la grabación) se traducen en fichas técnicas. Millares de ellas, minuciosamente clasificadas, representan el fruto escueto, pero preciso e irremplazable, de las fatigas de tantos viajes. A lomo de mula he recorrido regiones montañosas argentinas, desde San Luis hasta los límites con Bolivia, a través de valles, quebradas y cerros de tres a cinco mil metros de altura en Salta, Catamarca y La Rioja.

De este personal contacto con la vida del pueblo de mi tierra y del estudio científico de su folklore proviene lo más importante del material con el que he elaborado los cuadros siguientes.

\section{ORIGINALIDAD DE LOS NOMBRES DE PILA}

Los padrinos, teniendo o no el consentimiento de los padres, suelen producir el estropicio. Según es sabido, se prefiere para nombre de la criatura el del santo del día. La manera de determinarlo es consultar el almanaque, salvo en el caso de festividades muy solemnes, como San José o San Pedro, por todos conocidas. Pero no siempre se tiene en el rancho un calendario con el desarrollo completo del santoral y hay que consultarlo en el boliche o en la botica lejana. Cuando el emisario que acude en procura del dato no sabe leer o brinda más de la cuenta en la pulpería, se producen algunos equívocos pintorescos.

Por lo demás, los nombres de los santos, dicho sea con el debido respeto, no siempre son modelo de elegancia, de eufonía, de buen gusto actual. Es claro que nada obliga a elegirlos en tales casos, mas ¿quién se revela contra el mandato de la costumbre? No hay que olvidar tampoco que "el santo se enoja si se le desprecia el apelativo". El menor de los males resul- 
tantes es que la inocente criatura se llame Audifacio, Doril o Leovino; pero aún, si se trata de una mujer y responde al casi prohibitivo nombre de Venérea. Hay algo más. En los almanaques modernos se indican las festividades diarias, tanto religiosas como civiles, y el dócil sometimiento a la práctica consuetudinaria hace que en algunos casos se hayan aceptado como nombres propios las denominaciones oficiales de las fechas. $Y$ hasta con abreviaturas, tal como figuran impresas en la hoja del almanaque. De ahí que una señorita González se llame Fiesta Cívica, y otra, Clera (femenino inesperado de clero) ; no falta un rozagante señor Difunto, así anotado en el registro civil por haber nacido el 2 de noviembre. Por esta misma circunstancia, un vecino de un pueblo puntano apellidado Arce, fue agraciado con el nombre "Fest.-de-los-fiel.dif.", tal como queda escrito; tras el jeroglífico se descubrirá la frase "festividad de los fieles difuntos". Oí decir que a este vecino, en la localidad le llaman sencillamente "Don Festo".

Al mismo tipo de enigmas increíbles pertenece el caso ocurrido en el Chaco con un señor Traslad.-de-las-Reliq. Pérez nacido el día señalado en el almanaque como "Traslado de las reliquias de los santos mártires": así figuraba o así se lo dijeron a los padres y éstos lo acataron con imponderable sumisión.

El fervor político o las veleidades belicistas de algunos explican nombres como Hindemburg Rosales, Hitler Campos y Wilson Mendoza, documentados en Cuyo. Por fin, para no prolongar el muestrario, baste recordar a doña Desposoria Guatián (por la festividad del Desposorio de la Santísima Virgen) $y$, como broche final, el caso de un muchacho (digno hermano de la señorita Fiesta Cívica González, ya recordada) que vio la luz el 24 de mayo: por ser la víspera de la conmemoración patria argentina, merecía, sin duda, nombre adecuado, y a los padres se les ocurrió la fervorosa idea de llamarlo "Antipatrio"...

\section{LOS NINTOS EN EL FOLKLORE DEL NORTE ARGENTINO}

En mis viajes de estudio he observado con predilección lo que podríamos llamar el folklore infantil. Es interesante comprobar cómo los niños se encauzan en la corriente de la exis- 
tencia tradicional de la comunidad. Las familias campesinas del Norte suelen ser numerosas. Aún en los casos de mayor indigencia, los hijos son considerados un bien y recibidos como bendición. Pero a pesar de esto no muestran los padres efusividad tierna y demostrativa. Por temperamento son más bien replegados, herméticos, impasibles. Ahondando el análisis, no deja de descubrirse un matiz utilitario que se entremezcla con e! auténtico sentimiento. Los hijos son desde muy pequeños ayuda efectiva, imprescindible, en el rancho. Con respecto a los padres, representan algo así como un seguro para la vejez. No obstante, la llegada del crío es considerada un hecho natural que no altera el ritmo de la vida de familia.

Por su parte el bautizo no provoca festejo alguno. Y es explicable. El solo hecho de viajar al pueblo para hacer cristiana a la "guagüita" (criatura) acarrea problemas. :Qué difícil es concebirlos desde la gran ciudad! No se tiene idea de aquel aislamiento impresionante, en regiones abruptas y desoladas en las que el pueblecito más modesto dista docenas de leguas. Hay que preparar el viaje a pie o a lomo de mula, y afrontar las alturas, los vientos y las nevadas en invierno, las crecientes de los ríos en verano. Tales circunstancias no invitan a viajar con un niño recién nacido. Y no son los únicos obstáculos. No siempre en la aldea hay sacerdote permanente, o está en jira, y los misioneros pasan sólo una o dos veces por año. Puesto que se trata de un bautismo, deben coincidir en el viaje con los padrinos... y cuántas veces esa gente no puede abandonar el rancho, el riego de sus plantíos, el cuidado de sus majaditas. ¿Quién las conducirá durante esos días a los pastizales de los cerros? Por eso hay que esperar con paciencia, a veces por años, hasta que el momento oportuno llegue.

Entre tanto, sigue la vida hogareña su ritmo pausado y rutinario. Con un cajón o un canasto colgado con tientos de las vigas del techo improvisan la cuna. Así pueden imprimirle de vez en cuando un suave movimiento de vaivén $y$, al mismo tiempo, tenerla fuera del alcance de los animales domésticos... $\mathrm{y}$ de los otros.

Cuando el niño comienza a gatear y a sostenerse de pie pasa largas horas en la "tuncuna". Se trata de un hoyo cavado en lugar conveniente del patio del rancho. Por cierto no es una 
cueva donde se introduzca a la criatura como si fuera una rata. Es un pequeño pozo, cuidadosamente proporcionado en su dimensiones con el cuerpo del niño y no más hondo que la mitad de su altura. Lo tapizan bien, con cueros de oveja y mullidas mantas de lana. Allí calzan de pie al "changuito", que se mantiene bien sentado, no puede caerse, se entretiene con chucherías dejadas al alcance de su mano y está siempre bajo la vigilancia de la mamá. Cuando ésta tiene que alejarse carga su "guagua", llevándola "quepida" como dicen en el Norte. La acomoda a la espalda, envuelta en el manto o rebozo terciado en bandolera, y cuyas puntas ata sobre el pecho. Nada mejor para el niño, que va seguro, cómodo, abrigado, y al mismo tiempo ideal para la madre, que camina, viaja, cumple sus quehaceres con las manos libres, no entorpecida por el hijo cargado en brazos, como vemos en la ciudad.

Si en el curso de los años subsiguientes el desarrollo no es normal, el tesoro de experiencia familiar o la concepción mágica del mundo ofrecen la solución adecuada. Así, por ejemplo, si se trata de retardo o defecto en el habla, se busca un "chilicote", que es una especie de grillo, y se lo apoya levemente sobre la punta de la lengua del chico que amenaza quedar tartamudo.

Flagelos como la poliomielitis, que hoy tanto nos afligen, parecen haber hecho su aparición por aquellas regiones. Ignoro si técnicamente corresponde a la misma enfermedad, pero he visto chicos y adultos con las piernas paralíticas: son los llamados "suchos". Dicen que es bueno sentarlos en medio del corral, a las 12 del día, y cubrirles las piernas con la tierra y el estiércol que allí forman como un tibio colchón. Si el mal no cede, hay que carnear una vaca, abrirle la panza en canal y meter dentro medio cuerpo del "sucho" hasta que las entrañas del animal vayan perdiendo su calor.

De entre las varidísimas recetas, adecuadas para la curación de otros tantos males, algunas se refieren a dolencias del alma. Es el caso de los niños psíquicamente anormales, retardados, o, como dicen allá "idos". Quedan así a consecuencia de un susto que les ha enajanado el espíritu. Por eso hay que llamarlo... Esa creencia explica la ceremonia del "llamado del espirito", como he oído decir en el Norte: el curandero o la "medica" (acentuada también como grave esta palabra) toma 
una prenda de ropa del enfermo y la arrastra por los lugares donde se supone sufrió el susto y perdió el espíritu. Después de una serie de procedimientos, variables según las regiones, se le da al niño una vela encendida, y poniéndole la mano sobre la cabeza se llama, con tono quejumbroso, al espíritu ausente. Así se logra, dicen, que el niño vuelva a sus cabales.

Éstos y tantos otros casos que pudiera referir prueban que la vida diaria está como envuelta en una atmósfera sobrenatural. La absoluta fe en las fuerzas de ese mundo ultraterreno puede obrar efectos que parezcan milagrosos.

Pero no hay que olvidar que tras ese nimbo de prodigio y misterio sigue existiendo el concreto, el prosaico mundo de la dura necesidad cotidiana. $Y$ por desgracia, los niños tienen en él, desde muy pequeños, una dura faena que cumplir. Eso surge conociendo de cerca la vida y pasión de los pastores, en esos cerros de Dios, vecinos de las nubes; pero este pequeño mundo es demasiado denso para presentarlo de pasada y alguna vez merecerá artículo aparte. Los chiquilines ayudan también en el acarreo del agua y de la leña. Son tareas apremiantes y pesadas que la gente de ciudad no concibe. Allá, el agua potable tiene más valor que el otro. Hay que traerla en tachos o baldes desde la vertiente del cerro o del arroyo, que no siempre están cerca. La sequía o las crecientes los agotan o inutilizan a menudo. $\mathrm{Y}$ son incontables los acarreos de varias cuadras a fin de poder contar en la casa con el mínimo indispensable para beber y cocinar. La búsqueda de la leña es otro drama, agravado porque los montes naturales se van talando y cada día el viaje se hace más prolongado y fatigoso.

Las niñas, por su parte, ayudan a hornear el pan casero, a ordeñar las vacas y cabras, iniciando a ratos su práctica en los telares domésticos.

Claro que no todas las criaturas son hacendosas y diligentes. Las hay también, desde luego, traviesas y díscolas. A la hora de la siesta, sobre todo, salen a realizar correrías por los campos. Más que la represión posible de los padres, se advierte, también en esto, la presencia del mundo sobrenatural, que se entremezcla con lo cotidiano y se personifica en seres como el Duende, de quien Juan Carlos Dávalos dice con gracia que es: 
un hombre peticito, sombrerudo y lampiño, forzudo como un toro, travieso como un niño. Oculta en los bolsillos de su casaca enana, una mano de plomo y otra mano de lana. Pregunta a quien le halla cuál es la que prefiere, y si elegís de lana con la de plomo os hiere.

A la hora de la siesta cuando el sol reverbera, se aparece a los chicos debajo de la higuera. A jugar les convida con palabras cordiales, $y$ en la frente les deja tremendos cardenales.

Es interesante comprobar que el Duende y otros seres de esta laya, que para la gente de la ciudad no pasan de ser personajes fantásticos o meros motivos literarios, son para el pueblo nativo de aquellas tierras una realidad, que la mente concibe, que los sentidos creen percibir y que se corporiza como para hacer irrefutable la convicción de que lo sobrenatural integra, con toda evidencia, el mundo prosaico y cotidiano de la vida casera.

\section{RUTICHICO}

Con este curioso nombre se designa en Jujuy, Salta y Catamarca una pintoresca ceremonia que consiste en cortar por primera vez la cabellera del niño varón de seis o siete años. Como es imaginable, a esa edad los chiquillos pueden ostentar imponentes melenas; máxime si, como dicen en el Norte, son "quiscudos" es decir, de pelo lacio, abundante e hirsuto. Para atemperar el aspecto leonino y acaso para que los varones no parezcan niñas, trenzan el cabello en numerosas "simbitas"; esto explica que los diminutos personajes sean llamados "simbudos", con tono levemente burlón. Llegada la oportunidad propicia, se organiza la fiesta. Se reúnen los invitados en el rancho, donde los dueños de casa agasajan con viandas y bebidas. Desahogados los ánimos con jaranas, bromas, cantos y bailes se cumple la ceremonia principal, con cierta solemnidad. Los padrinos de la criatura pasan a ocupar, junto con ésta, lugar de preeminencia en la reunión. Aparecen las tijeras y una bandeja. Después de preparativos y circunloquios, se inicia el corte de la primera trenza o "simbita". Es esto privilegio y distinción de los padrinos, que retribuyen largamente el honor 
regalando al ahijado dinero, prendas de plata o cualquier otro obsequio, que depositan en la bandeja. A veces simbolizan con hojas de coca, por ejemplo, otro tipo de presente, como cabezas de ganado, alguna vaquita si el paisano es pudiente y rumboso, y si no, cabras o corderos para ir formando la majada.

A este primer corte solemne sigue el practicado por cada uno de los circunstantes, obligados también, por cierto, a una contribución obsequiosa de acuerdo con sus posibilidades, parentesco y relación.

Terminada la fiesta, los brindis y los augurios, se destrenzan las "simbitas" o "amarritos", como también se les llama por estar atados o "amarrados" con cintas.

Se acondiciona la cabellera y es llevada a la iglesia donde se le ofrendan a la Virgen. Se hace en cumplimiento de una promesa formulada por los padres en ocasión afligente de enfermedad o grave riesgo sufrido por el rapaz. Por eso a los "simbudos" se les llama también "promesados".

Como se ve, se trata de una fiesta familiar que tiene proyección religiosa. Pero lo interesante es vislumbrar lo que yace bajo las actuales apariencias. Esto no fue siempre así. Ya el nombre quichua "rutichico" o "rutuchicu" puede suscitar la sospecha. En efecto, los incas precolombinos llamaban "rutuchíkuy" a la acción de dejarse cortar el cabello, palabra en la que 'rutu" equivale a corte, esquila, tonsura o siega de la mies. Esta misma ceremonia recibe en Jujuy y otras regiones norteñas los pintorescos nombres de "chujcharruta", "chujchapelo" y "guaguarruta", que se aclaran sabiendo que "chujcha" es cabellera, pelo de personas y animales, y "guagua", criatura de uno $u$ otro sexo.

Todos los términos aluden, pues, al hecho material del corte del cabello; pero no se trataba en tiempos del incanato de una simple operación peluqueril. Tenía entonces el significado de una ceremonia de transición, de solemnizado pasaje del primero al segundo período de la infancia. Es uno de los tantos casos, universales en cuanto a su sentido profundo, aunque variadísimos por su forma y ceremonial externo, de ritos de "pasaje", entendiendo por tal el tránsito figurado de una edad a otra, como en este caso, o la entrada en la pubertad. Se pueden también referir a estos ritos los que se practican al cambiar 
de estado (de soltero a casado, por ejemplo) y aún los correspondientes al acto dramático de la partida sin retorno, del "pasaje" hacia el mundo de ultratumba.

La fuerza de la tradición ha mantenido esta verdadera supervivencia autóctona americana que, incrustrada en el folklore actual, ha transferido su función a otros planos dando fe de la vitalidad secular de la tradición.

\section{AMANAMIENTO}

Otra etapa trascendentai en la vida es la formación de la familia. Alguna vez, a despecho de todas las oposiciones familiares, la moza se "juye" de la casa con el galán, originando conflictos y consecuencias eternos. En otros casos, la unión, iniciada de hecho, se consolida con el acuerdo y consentimiento expreso o tácito de todos. Por fin, estos matrimonios "de facto" llegan a configurar verdaderas instituciones, como el amañamiento. Es una especie de "matrimonio de prueba" que antecede a la formalización hasta comprobar si los caracteres se avienen recíprocamente y, sobre todo, si el hogar es bendecido con lozana descendencia. Esto último, no tanto por exigencia sentimental, sino por imperio de la necesidad económica. Por otra parte, la esterilidad femenina, según el consenso social lugareño, ocupa nivel aún más bajo que la conducta liviana en la tabla de valores colectivos.

Comprobadas las dos condiciones básicas: compatibilidad de caracteres y descendencia normal, no oponen resistencia a la regularización de su matrimonio. Al trámite de la anotación en el registro civil llaman "civilarse" o "civiliarse" y por lo tanto, cumplido este requisito, la pareja de "amañaos" se convierte en "civiliaos". Por fin, con la consagración del sacramento religioso, demorado a veces por razón de distancia con respecto a la capilla lúgareña o a la iglesia del pueblo, todo llega a su culminación feliz. Los integrantes de la pareja "amañada" se convierten así en legítimos e inobjetables "matrimoniaos".

\section{FLECHADA Y CORPACHADA DE LA CASA}

Supongamos que la constitución de la flamante familia coincida con la inauguración de una nueva vivienda. Los ran- 
chos del Noroeste, construídos por sus propios moradores con los elementos que la naturaleza les ofrece: piedra, barro, troncos, caña, paja, suelen ser inaugurados cumpliendo la ceremonia de la "ilechada".

Para esto se cuelgan de las cañas o vigas del techo algunos huevos, y a falta de éstos, quesitos tiernos de cabra. Los circunstantes, provistos de pequeños arcos improvisados con varillas y ramas flexibles les disparan flechas diminutas.

La elección de quesos y huevos como blanco deja entrever lo que hay de rito de fecundidad en esta ceremonia. La misma idea está latente también en la "corpachada". Los convidados, especialmente los contrayentes, padrinos y padres, se congregan alrededor de un pequeño pozo cavado en el piso de tierra de la habitación, en torno del cual se colocan ollas con comida. Provistos de cucharas de madera trasiegan algunas porciones al pocito, que recibe también ofrendas de chicha (bebida fermentada, a base de maíz), coca, alcohol, cigarrillos, etc. Se cubre todo con una "laja" o piedra chata y lisa y se empareja el piso terroso. Luego el dueño de casa, o alguien en su representación, se apoya con codos y rodillas en el suelo y formula de viva voz la ofrenda a Pachamama, diosa de la tierra y la fecundidad, rogando por la dicha de los ocupantes del rancho.

Suele iniciarse entonces el torneo de la "flechada": al que acierta el tiro, rompiendo la cáscara de un huevo o ensartando un quesito, se lo premia con vítores y jarros de bebida. Las flechas que no dieron en el blanco se incrustan en el techo de paja, de donde aconsejan no quitarlas, pues cumplen la función mágica de "pinchar" los ojos al espíritu maligno de la casa, impidiendo así que arrebate la felicidad de sus moradores.

\section{LAS BOLEADAS}

No todo es, desde luego, fiesta y jolgorio. La ruda faena, rutinaria y pesada, se reanuda de inmediato. Según las regiones, será el cultivo de la tierra o la atención del ganado, el desmonte o la pesca, el tejido en los telares o el arreo a través de llanuras y montañas.

Del abigarrado muestrario de tareas populares, recordaré sólo una, para matizar lo actual con lo histórico reciente: las 
boleadas de potros cimarrones, de ñandúes y de guanacos en las pampas. Trabajo que fue a la vez deporte y a menudo proeza, sintetizó en sí el esfuerzo útil de la faena pastoril y el brío de la caza, exaltada por momentos a la categoría de hazaña épica. Apasionó a los indios, enseñoreados del caballo y constituyó atractivo insuperable para los gauchos.

La técnica fue semejante en uno y otro caso. Exigía, como en la guerra, un jefe avezado. Se tomaban las necesarias providencias, basadas en un profundo conocimiento, tanto del terreno como de los hábitos de los animales perseguidos. Cuando se trata de "choikes", como se les llama en el Sur a los ñandúes, los cazadores reciben hasta hoy el nombre de "choikeros".

Las boleadas han sido descritas por hombres de ciencia, escritores y poetas. A través de cien relatos se perfila la imagen viva de la hazaña cinegética. Va la partida hacia las aguadas y praderas donde la experiencia augura buenos resultados. Se avistan a distancias increíbles las manadas; se disponen estratégicamente las fuerzas; despliéganse en línea de batalla, que comienza siendo raleada fila, luego se tuerce en media luna, se va cerrando en pinza colosal hasta que, logrado el círculo, comienza la persecución y la matanza en este improvisado seto de caza, que se dilata por leguas. Cada uno lleva varios pares de boleadoras arrolladas en la cintura, las cuales van entrando en acción a medida que el caballo, diestro y nervioso, se va aproximando al objetivo. Ya inician las bolas de piedra su ronda de muerte voltejeando sobre la cabeza del cazador; ya el brazo nervudo y certero las arroja; ya cae la pieza en un revoltijo desesperado de patas y tientos en medio de la polvareda de la brutal rodada; ya refrena el gaucho, salta, degüella, retoma las boleadoras, monta y sigue como exhalación en procura de la víctima próxima. Tiempo habrá luego para recorrer el teatro de la hazaña y con pareja destreza desollar guanacos o desplumar ñandúes, carneando los trozos más apetitosos para el inmediato asado suculento.

\section{EL LOBISON}

En la realidad concreta, con frecuencia prosaica y rutinaria, que constituye la vida cotidiana del pueblo, caben como 
compensación las ceremonias y las fiestas y en algún caso hasta la épica aventura. No falta, no podía faltar, el toque escalofriante de lo supersticioso y sobrenatural. Suele aparecer, con su impacto terrorífico, en el curso de la actividad doméstica. Su faz espectral hace su aparición inesperada en el seno del mundo familiar y circundante, sale de entre bastidores al escenario donde desempeña la existencia aldeana su cotidiano papel.

En un pueblo cualquiera de Corrientes, de Misiones, del Norte argentino, del Paraguay o del Uruguay, de Bolivia o del Brasil vive una familia común y normal. Son nuevos en el lugar, laboriosos y honestos. El matrimonio es prolífico. Al cabo de años nació el séptimo hijo varón. Los lugareños, conocedores de las creencias ancestrales, lo comentaron significativamente. Pero nada ocurrió por mucho tiempo. Siendo ya aquel niño un mocetón, se lo vio desmejorar, andar decaído, macilento, desaliñado y hasta maloliente. Los viernes por la noche salía del rancho, sin duda para andar de parranda, pues regresaba de madrugada, fatigado y maltrecho. El viejo recelo reverdeció. Un sábado muy de mañana contó un vecino, azorado, que la noche anterior había tenido que luchar con un monstruo negro, mezcla de perro y jaguar, con grandes orejas que producían un traqueteo lúgubre, el cual se apareció en el chiquero de su casa. Cuando al rato vieron al mozo, desencajado y con una mano vendada, no cupo duda: jera un Lobisón!

Todos ataban cabos. Sabían, desde tiempo inmemorial, que el séptimo hijo varón (o el séptimo después de seis mujeres) puede sufrir la horrible metamorfosis. Para esto, a medianoche del viernes, se revuelca hacia la izquierda sobre inmundicias y reza un credo al revés. Desde que suena la última campanada de medianoche hasta el primer canto del gallo queda convertido en un monstruo repelente que hoza en los estercoleros y gusta engullir golosamente sangre de criaturas, remover las tumbas en busca de cadáveres y devorar carroña. El alba torna a su forma humana, pero queda exhausto. Soporta su destino como una maldición. A veces parece que purgara las faltas de los padres, condenados por pecado de adulterio o incesto, especialmente entre comadre y 
compadre o padrino y ahijada. El nefando sortilegio puede ser disipado por quien afronte al Lobisón y lo hiera con cuchillo. La maldición se lava con su sangre.

Así pasó con el joven del cuento y todo volvió poco a poco a la normalidad. En cierto sentido puedo decir que el relato no es fantástico. La creencia en los hombres-lobos existe en Europa desde los más remotos tiempos, con las variantes consabidas. La palabra Lobisón o Lobisome, de origen portugués (Lobishomem) tiene su equivalente en todos los idiomas europeos, desde el Loup-garou francés hasta el Obototen ruso, desde el Wahwolf germano hasta el Licántropo griego (de 'Iycos', lobo, y 'ánthropos', hombre), término de donde deriva licantropía, que alude a estas transformaciones de seres humanos en animales monstruosos.

El tema del hombre-lobo aparece en autores clásicos como Plinio el Antiguo, Heródoto y Ovidio; Cervantes trató de él con cierta extensión en los Viajes de Persiles y Segismunda. Tiene hoy difusión universal, aunque con matices regionales, como ocurre con todos los fenómenos folklóricos. Los mismos guaraníes lo llamaron "Yaguareté-abá" (indio-tigre) y bajo esta forma lo estudió Juan B. Ambrosetti.

Lo que más interesa destacar es que este caso prueba una vez más una característica cultural de los grupos populares, de las comunidades de tipo "folk": estas creencias, supersticiones, leyendas y mitos no son, como para la gente letrada y racionaljsta, intelectualizada y libresca, meros relatos de valor sólo anecdótico y narrativo. Para el pueblo, apoyado en el testimonio de la experiencia tradicionalizada, son entes posibles, reales, que llegan a compartir su vida, integran la realidad circundante, perturban la mente $\mathrm{y}$ hasta se convierten en árbitros del destino de los simples mortales.

\section{LAS ANIMAS SABOREAN LAS OFRENDAS}

Como es sabido, el 2 de noviembre, Día de los Fieles Difuntos y la víspera, consagrada a Todos los Santos, verdaderas multitudes concurren a los cementerios llevando flores. En regiones campesinas del Noroeste argentino, lo mismo que en toda Iberoamérica, subsiste la costumbre de preparar 
"ofrendas"; aunque suscitadas por idéntico motivo y animadas por el factor común de la fe cristiana en la supervivencia del alma, configuran un fenómeno diverso. En cierto modo constituyen una forma de culto doméstico de los muertos. Cuando decimos "ofrendas" con respecto a esta costumbre, abreviamos la expresión completa: "ofrendas para las almas". En algunas provincias se concreta su carácter, pues se dice "cena de las almas".

¿Cuánto ajetreo se produce en algunas casas ante la proximidad de la celebración! A veces, como si se tratara de un rito, las dueñas de casa se visten de luto para cumplir estos menesteres. Sacrifican corderos y gallinas y se afanan en mil preparativos para la digna presentación de la cena.

Lo inesperado es que se trata de una cena para los finados de la familia a quienes se recuerda el 2 de noviembre. En primer término, se preparan platos que hayan sido de su agrado en vida... ; pero nunca faltan los más suculentos y tradicionales, como empanadas y asado, quesos y quesillos, y mil delicias de la cocina y la repostería lugareñas.

No es sin embargo un simple banquete, pues no faltan los aspectos ceremoniales. Después de arreglado el rancho convenientemente, se desocupa, aunque sea a medias, una de las habitaciones; se tiende esmeradamente la mesa y en la noche del $L^{9}$ de noviembre se sirven los platos y viandas, de las que nadie osaría probar bocado. Se adorna la pieza con flores, se encienden velas; no falta en la mesa un vaso de agua, bendita si se puede conseguir, y en las fuentes se coloca una cañita $o$ pajita hueca.

Esto último exige una aclaración. La comida es así preparada porque se cree en la venida real de las almas, congregadas por este acto de recuerdo y de homenaje. No se concibe que las almas coman material y groseramente los bocados, pero pueden testimoniar su complacencia y gratitud probando sólo el "zumito", absorbiendo la sutil, inapreciable "sustancia" de las ofrendas. Y por eso han de hacerlo a través de la pajita hueca, que es, por cierto, más un símbolo que un utensilio.

Entretanto, los miembros de la familia suelen quedarse en la misma habitación, rezando como en un velorio. A veces 
cubren la puerta con una manta y se retiran respetuosamente, para facilitar la llegada de las ánimas.

En otras partes juegan, aunque la circunstancia no parece muy apropiada; juegan, por ejemplo, a la taba, pero no por dinero, sino por rezos... Es un recurso con el que adaptan la devoción a la necesidad de acortar la larga noche de espera. Se tira la taba, como en un partido común, y el que pierde debe entrar donde están las "ofrendas" para rezar las Avemarías que se haya convenido.

Todo esto ocurre, por lo común, fuera de la habitación donde se han preparado las "ofrendas". Es más: en la puna jujeña abandonan el rancho y se reúnen en la casa de un vecino, casa que con frecuencia no queda nada cerca.

Esto me recuerda una anécdota que confirma este detalle $\mathrm{y}$ da idea de aquellas ingenuas creencias.

Un capataz extranjero recién contratado, bajaba de un campamento minero al pueblo, adonde esperaba llegar de mañana para despachar telegramas urgentes relacionados con la explotación. El hombre, como forastero, desconocía el lugar y las costumbres campesinas. Había viajado toda la noche, al paso de la mula. Con la premura, olvidó las provisiones para el camino. Como había debido partir antes de la cena, a eso de la medianoche el estómago le reprochaba sordamente tamaña imprevisión. En eso, al pasar frente a un rancho aislado que se levantaba junto al sendero, advirtió con alegría que estaba iluminado. Decidió hacer la intentona de restaurar sus fuerzas, debilitadas por la cabalgata, la aspereza del camino de montaña y el ayuno involuntario. Desmontó en el patio del rancho, golpeó las manos, saludó a gritos, llamó en todos los tonos sin que nadie respondiese. Extrañado, decidió entrar en la habitación iluminada. Apartó la manta que servía de puerta y vio con sorpresa, a la luz de varias velas, el reconfortante espectáculo de una mesa servida con profusión de manjares. Por prudencia, resistió un rato la tentación, llamó reiteradamente, recorrió los alrededores del rancho sin encontrar un alma... Por lo menos un alma encarnada en un cuerpo, pues las almas auténticas estarían congregadas a la mesa... ya que, como se habrá adivinado, se trataba de unas "ofrendas". Nuestro hombre decidió alimentarse con tan pro- 
videncial banquete y lo hizo a conciencia. Montó de nuevo en la mula y siguió viaje.

Vueltos los miembros de la familia a la casa, lejos de desconcertarse ante la evidente disminución de las raciones, lo atribuyeron a especial complacencia de las ánimas, que esta vez no se habían contentado con el "juguito".

No en todos los ranchos se preparan "ofrendas". Quedan a cargo de las familias que tengan "alma fresca". Con esta expresión se alude al ánima del deudo perdido en el curso del año, con la salvedad de que se excluyen los casos de duelos muy recientes, ocurridos, por ejemplo, la víspera del 2 de noviembre. Se supone que el alma no habrá tenido tiempo de hacer su viaje celestial, dar cuentas a Dios y retornar a recibir el homenaje de las "ofrendas". La celebración queda postergada para el año siguiente.

Pasada la noche, y reconfortadas las almas, las "ofrendas" son luego repartidas en porciones equitativas entre todos los asistentes, pero ni aun así olvidan el primordial destino de esta comida. Según la provincia, varía la práctica: en unos casos queman algunas raciones, como homenaje; en otras, las entierran junto al fogón. Algunos, en forma casi procesional, van hasta un lugar escogido, no lejos de la casa, y allí entierran unas pocas porciones, junto con hojas de coca y algo de chicha, vino o alcohol. En esta forma, dice, "dan de comer a la tierra".

Se trata de una verdadera ofrenda ritual a la tierra, semejante a otras que se cumplen, por ejemplo, al inaugurar el rancho recién construido, o al iniciar la siembra, o antes de emprender una cacería de guanacos en los cerros. Pachamama, espíritu divinizado de la tierra, recibe en tales ocasiones las ofrendas. Pero en este caso, está latente la superstición de que la tierra es la que arrebata la vida de quienes andan sobre ella. Por eso hay que "darle de comer": tal vez, ya saciada, no intente arrebatar nuevas almas para su reino subterráneo.

Por lo dicho, parecerá que es aquélla una manera demasiado suculenta de recordar a las almas; pero hay que tener en cuenta, como ante cualquier fenómeno folklórico, más la función y la motivación que la apariencia externa y material. 
Aquí pasa a segundo plano la comida considerada como objeto de goce y de gula o mero alimento. Lo importante es su valor ceremonial y propiciatorio. No es sino un testimonio del recuerdo suscitado por los que se han ido y una especie de rito por medio del cual se ruega bienaventuranza para las almas que todavía no gozan de la eterna paz. Por cierto que no falta el propósito más personal de lograr una valiosa intercesión sobrenatural y aún de evitar que las almas sientan el impulso de retornar a la tierra llenando a los vivos de perturbación y sobresalto.

Como se ha visto, a través de ejemplos que podrían ser renovados en sucesión infinita, el folklore con sus costumbres y ritos, leyendas y fiestas, ceremonias y creencias, es como un inagotable comentario de los acontecimientos y etapas principales de la vida popular. Ante valla alguna se detiene, y sobrepasando lo real y concreto, se aventura en la atmósfera de lo insondable y en los ámbitos de lo sobrenatural. No sólo borda comentarios sabrosos, sino que interpreta, instruye, da normas y hasta presagia. Acaso estas voces del folklore nos resulten sencillas y hasta pueriles; pero no olvidemos que con frecuencia tales voces interpretan así lenguajes milenarios por cuyo intermedio el espíritu humano, desde el amanecer del mundo, ha dicho a los hombres cosas profundas y trascendentales con expresiones de apariencia ingenua y baladí.

... Y quien tenga oídos para oír, que oiga.

Augusto Raúl Cortazar

Universidad de Buenos Aires

Argentina 
